\title{
UÁQUIRI
}

Revista do Programa de Pós-Graduação em Geografia

UÁQUIRI - PPGGEO, v. 2, n. 1, p. 144 - 157, ano 2020.

Home page: https://periodicos.ufac.br/index.php/Uaquiri

\section{ESTADO E INDUSTRIALIZAÇÃO: UM ESTUDO DE CASO DA DOM PORQUITO E DA ACREAVES NO ESTADO DO ACRE}

\author{
Alana Katlhin dos Santos Bezerra ${ }^{1 *}$, Ana Karolina Fernandes Mourão ${ }^{2}$, \\ ${ }^{D}$.Karina Furini da Ponte ${ }^{3}$ \\ ORCID: https://orcid.org/0000-0002-9802-5905; https://orcid.org/0000-0002-0600-4745; \\ https://orcid.org/0000-0002-5780-6449
}

${ }^{1}$ Graduanda em Geografia Licenciatura e bolsista do projeto de Iniciação Científica (PIBIC) pela Universidade

Federal do Acre, Rio Branco, Acre, Brasil; ${ }^{2}$ Graduanda em Geografia Licenciatura e voluntária do projeto de

Iniciação Científica (PIVIC) pela Universidade Federal do Acre, Rio Branco, Acre, Brasil; ${ }^{3}$ Professora do

Programa de Pós-Graduação do Mestrado em Geografia, dos cursos de Licenciatura e Bacharelado Geografia da Universidade Federal do Acre, Rio Branco, Acre, Brasil e orientadora do projeto de Iniciação Científica (PIBIC e PIVIC), Rio Branco, Acre, Brasil.

*alanabezerra419@gmail.com

Recebido em: 29/04/2020. Aceito em: 13/05/2020. Publicado em: 22/06/2020. DOI:

\begin{abstract}
RESUMO
O artigo apresenta um estudo de caso sobre a industrialização no estado do Acre com foco nas indústrias de suinocultura Dom Porquito e de avicultura Acreaves. Para isso, partimos de uma análise do processo de industrialização no Acre, enfatizando suas peculiaridades e suas características. O objetivo principal do artigo é analisar a relação entre o setor público (governo do estado do Acre) e o capital privado através de suas dinâmicas territoriais e industriais de produção, além de identificar o papel do campesinato nesta forma de organização produtiva. Como metodologia, foram feitas discussões teóricas que tratam da temática, assim como visita técnica e entrevista realizada com o diretor técnico da Dom Porquito e da Acreaves. Portanto ao compreender a dinâmica industrial no Acre, é possível refletir sobre sua realidade e seus percalços, bem como entender o papel do setor produtivo industrial para com o campesinato.
\end{abstract}

Palavras Chave: Estado; Industrialização; Dom Porquito; Acreaves

\section{STATE AND INDUSTRIALIZATION: A CASE STUDY OF DOM PORQUITO AND ACREAVES IN THE STATE OF ACRE}

\begin{abstract}
The article presents a case study on industrialization in the state of Acre with a focus on the pig farming Dom Porquito and poultry farming Acreaves. For this, we start from an analysis of the industrialization process in Acre, emphasizing its peculiarities and characteristics. The main objective of the article is to analyze the relationship between the public sector (government of the state of Acre) and private capital through their territorial and industrial dynamics of production, in addition to identifying the role of the peasantry in this form of productive organization. As a methodology, theoretical discussions were made that deal with the theme, such as technical visit and interview conducted by the technical director of
\end{abstract}


Dom Porquito and Acreaves. Therefore, in order to understand an industrial performance in Acre, it is possible to reflect on its reality and its mishaps, as well as to understand the role of the industrial productive sector for the peasantry.

Key Words: State; Industrialization; Dom Porquito; Acreaves.

\section{ESTADO E INDUSTRIALIZACIÓN: UN ESTUDIO DE CASO DE DOM PORQUITO Y DE ACREAVES EN EL ESTADO DE ACRE}

\section{RESUMEN}

El artículo presenta un estudio de caso sobre la industrialización en el estado de Acre con enfoque en las industrias de porcicultura Dom Porquito y de avicultura Acreaves. Para eso, empezamos por el análisis del proceso de industrialización en Acre, enfatizando sus peculiaridades y características. El principal objetivo de este artículo es analizar la relación entre el sector público (gobierno del estado de Acre) y el capital privado a través de sus dinámicas territoriales e industriales de producción, además de identificar el papel de los campesinos en esta forma de organización productiva. Como metodología, se hicieron discusiones teóricas que tratan de la temática, así como visita técnica y entrevista realizada con el director técnico de Dom Porquito y de Acreaves. Por lo tanto, al comprender la dinámica industrial en Acre, es posible reflexionar sobre su realidad y sus obstáculos, además de entender el papel del sector productivo industrial para con los campesinos.

Palabras Clave: Estado; Industrialización; Dom Porquito; Acreaves.

\section{INTRODUÇÃO}

Dentro da lógica capitalista, a atividade industrial representa uma importante atividade econômica, sendo esta responsável pelo processo de transformação do espaço, de forma que ambos vão se reproduzindo para atender as necessidades um do outro. Desta forma, o presente artigo tem como foco realizar discussões em torno do processo de industrialização no estado do Acre destacando-se as indústrias Acreaves e Dom Porquito, bem como o papel do estado, do capital privado e dos camponeses integrados.

Diante disso, partiremos de uma análise histórica do processo de industrialização no Acre, destacando suas principais características e peculiaridades. Ao discutir a industrialização no estado, abordaremos os principais fatores que propiciaram o investimento industrial na região, assim como o modelo econômico que se faz presente nas indústrias do estado (PPC), descrevendo e analisando como se realiza essa parceria entre estes três setores (público, privado e comunitário) e qual o papel de cada um deles neste modo de investimento e produção.

Com isso, foi possível compreender como a indústria se articula diante das dinâmicas econômicas, políticas e sociais presentes no estado. Para além disto, também abordaremos o papel do estado diante da indústria, onde o mesmo se apresenta como um grande incentivador 
das atividades industriais no Acre, isto em decorrência da objetivação do desenvolvimento industrial, geração de emprego, visibilidade econômica, dentre outros. Sendo assim, é abordado também o papel do pequeno produtor, de forma que seja possível compreender a sua participação neste processo de industrialização e qual sua relação com a indústria.

O artigo também trará uma breve caracterização do modelo de produção adotado pelas duas empresas (Dom Porquito e Acreaves), demonstrando a relação existente entre os quatro setores (inseminação, fábrica de ração, embutidos e frigorífico) e o campesinato integrado.

Como metodologia, partiremos de levantamentos e discussões de referências sobre industrialização no Brasil e no Acre, com ênfase para artigos sobre a Acreaves e a Dom Porquito. Outra atividade foi uma visita técnica às unidades industriais Dom Porquito e Acreaves, bem com uma entrevista com o diretor responsável pelas empresas, Alder Cruz, que teve como objetivo entender a tríade: Estado, indústria e campesinato, diante da especificidade da cadeia produtiva de suínos e aves na regional do Alto Acre.

Portanto, a conclusão da pesquisa de Iniciação Científica realizada ao longo dos anos de 2018 e 2019, nos permitiu compreender a situação do processo industrial no estado do Acre, seus gargalos e avanços, como também abordar exemplos de indústrias vinculadas ao produtor rural e que tem como foco a produção alimentícia.

\section{A INDUSTRIALIZAÇÃO NO ESTADO DO ACRE}

O processo de industrialização no Brasil ocorreu de forma tardia, isto quando comparado aos outros países industrializados como Inglaterra, Estados Unidos e Japão. Conforme Mendonça (2004) foi somente no final do século XIX e início do século XX, a gênese da industrialização moderna brasileira. Na Era Vargas, compreendida no período de 1930 a 1945, foi o momento em que o crescimento da indústria superou o da agricultura no Brasil, assumindo o papel de recuperação da economia devido à crise do café. O principal agente para essa mudança foi o Estado transformando-se em investidor de indústrias pesadas, criando várias empresas estatais como meio de alavancar a industrialização nacional e substituir a importação.

O processo de industrialização brasileira sempre foi influenciado pelo Estado, ora assumindo o papel de protagonista com as empresas estatais, como ocorreu com Getúlio Vargas; ora transferindo ao capital privado seja nacional ou com a internacionalização da economia como caracterizou o período das décadas de 1950 até 1980 com Juscelino Kubitschek e no período dos governos militares. 
A atividade industrial é a grande responsável pela reprodução do espaço, pois de acordo com cada tipo de produto e a dimensão da indústria, demandará exigências diferenciadas. Entretanto, de maneira geral, a infraestrutura, a mão de obra, a proximidade de outras indústrias complementares, a estabilidade política e o mercado consumidor, são elementos que atraem a indústria. Desta forma, o espaço é produzido para atender a necessidade da produção, e estas seriam as transformações que o Estado e o capital passariam a tomar como medidas para sua "modernização". Como salienta Carlos (1988, p.15), "o espaço vai se produzindo para atender às necessidades da produção e das relações que essa produção, somada à circulação, distribuição e troca determinam."

Moreira (2016) destaca a relação de reciprocidade de influência entre o meio e a indústria, assim como a relação homem-natureza e o modo de representação do mundo e tempo. Deste modo, entendemos as transformações sociais, econômicas e políticas que uma indústria pode transportar para determinados lugares. As mudanças sociais centradas no desenvolvimento urbano e na nova força de trabalho assalariada, a econômica voltada para o grande número de investimentos privado e público, sendo que esses investimentos públicos podem ser de forma direta (como sócio, a exemplo do modelo Público Privado Comunitário) ou de formar indireta (com o desenvolvimento de infraestrutura e acesso a créditos e financiamentos).

Portanto, o Estado sempre teve um papel relevante para as demandas das indústrias, pois sua atração pode significar geração de empregos, aceleração do processo de urbanização, maior arrecadação.

No estado do Acre, quando nos referimos a sua industrialização, é perceptível o quanto este processo é tardio e ainda está em construção. Mas para compreender melhor esse momento de industrialização no estado é preciso analisar o processo histórico do sistema global do capitalismo, que na década de 1970, passou por uma crise avassaladora, o que resultou em seu processo de reestruturação e assim, novos modelos de acumulação como o caso da construção do conceito de desenvolvimento sustentável enquanto possibilidade de apropriação da natureza para a lógica do capital (PONTE, 2014).

Sendo assim, no ano de 1999, quando Jorge Viana assume o poder estadual dá início a uma fase de "modernização no Acre". Segundo Moura (2016), o objetivo de Jorge Viana era conciliar o crescimento econômico junto à preservação da natureza, ou seja, trazendo a proposta do desenvolvimento sustentável. A ideia "vendida" seria um modelo que busca a interação da 
economia e a ecologia, onde desta forma, faz-se o uso dos recursos naturais em diversas dinâmicas econômicas, mas de forma sustentável, ou seja, não comprometendo-os.

Este modelo é utilizado mundialmente dentre várias esferas econômicas como forma de "aprovação" à utilização dos recursos naturais, e a indústria é uma delas. Entretanto, esta proposta possui suas façanhas, onde nada mais é do que a mercantilização da natureza amparada por leis que subsidiam a exploração em massa de maneira mascarada. Conforme reforça Ponte (2014):

O novo desenvolvimento, difundido pelo poder público, deveria ser sustentável, isto é, modernizar e dinamizar a economia e corrigir as injustiças sociais e, ao mesmo tempo, conservar a floresta e respeitar a cultura dos vários povos que compõem a sociedade acreana. Com o direcionamento das políticas públicas para uma estratégia de 'Desenvolvimento Sustentável' (MORAIS, 2008 apud PONTE, 2014, p.162).

Porém, o estado encontrava-se sem meios financeiros para realizar investimentos, logo, o discurso para este projeto foi alinhado dentro das diretrizes estabelecidas pelos mecanismos de crédito do Banco Interamericano de Desenvolvimento (BID) e do Banco Mundial e assim, facilitar a aquisição de financiamentos para alavancar os projetos vinculados à sustentabilidade. Com isso, a adoção do modelo de sustentabilidade proporcionou vários recursos financeiros para os investimentos do governo do estado, inclusive nos setores industriais.

A partir disto, podemos concluir que a indústria no Acre passa a estar atrelada a economia verde, que prega o acúmulo de capital sustentável. O capitalismo verde utiliza da exploração e extração de recursos gerando uma capitalização, ou seja, os recursos naturais passam por um processo de mercantilização com o slogan da sustentabilidade.

Mas para que a indústria pudesse estabelecer-se na região eram necessários vários fatores, por exemplo: infraestrutura, mão de obra, mercado consumidor, créditos etc. Para atender a essas demandas de estruturação do território, o estado também se utilizou dos Planos Plurianuais e incentivos fiscais.

Os Planos Plurianuais (PPA) são instrumentos previstos na Constituição Federal para organizar e viabilizar as ações públicas, com ele é declarado o conjunto de políticas públicas de um governo para o período de 4 anos e os caminhos para viabilizar as metas previstas. Além de outras ações, este proporcionou o recebimento de indústrias, como os complexos agroindustriais de articulação local e regional no estado do Acre.

Estes complexos agroindustriais são fundamentados basicamente em um modelo de integração das técnicas entre os setores indústrias, pois houve uma adaptação sendo que ela 
mesma é capaz de produzir e atender as demandas do mercado consumidor, e ainda realizar a integração do camponês ao processo produtivo.

Segundo os PPAs de (2004-2007), (2008-2011) e (2012-2015) que propunham, dentre outras propostas, um desenvolvimento industrial no estado, passou a focar seus recursos advindos do BNDES para a criação dos complexos agroindustriais.

Nesse sentido, foram criados o Complexo de Peixes, Peixes da Amazônia S.A, em 2011, com o objetivo de produzir peixes regionais amazônicos para comercialização local, nacional e internacional. Recebeu um investimento do Governo do Acre de R \$ 53 milhões para a criação de uma unidade de alevinagem, fábrica de ração e frigorífico, porém a empresa não conseguiu se estabelecer e se consolidar, devido a falta de comércio, matéria prima, infraestrutura e mão de obra qualificada. Além do Complexo de Peixes, tem-se também a instalação da Dom Porquito e da Acreaves, que serão discutidas no próximo item.

Com relação aos incentivos fiscais, o precursor foi o Decreto $n^{\circ} 4.196$, de $1^{\circ}$ de outubro de 2001, que instituiu o Programa de Incentivo Tributário para Empresas, Cooperativas e Associações de Produtores do Setor Industrial, Agroindustrial, Florestal, Extrativo Vegetal e Industrial Turística do Estado do Acre. Sua finalidade foi conceder incentivos às tais atividades que já se encontram instaladas ou que vierem a se instalar no estado.

Tal política foi reforçada pelo Decreto $\mathrm{n}^{\circ} 4.198$, de $1^{\circ}$ de outubro de 2001 , em que aprova a Política de Incentivos às Atividades Industriais no Estado do Acre e como instrumento legal cria-se a Comissão da Política de Incentivos às Atividades Industriais no Estado (COPIAI), enquanto importante órgão de execução e regulação da política de incentivos.

Para serem contemplados com a política de incentivos, tais empreendimentos industriais devem se enquadrar em alguns critérios, como: geração de emprego com mão de obra prioritariamente local; implantação, ampliação e modernização dos setores industriais com incorporação de tecnologias modernas e competitivas; geração de renda nos setores produtivos a partir do beneficiamento das matérias primas regionais; promover a interiorização das atividades econômicas, dentre outros critérios. (ACRE, 2001a, 2001b).

Outra importante legislação promulgada pelo governo do estado do Acre foi a Lei $\mathrm{n}^{\mathrm{o}}$ 2.548, de 17 de fevereiro de 2012, que cria o Programa de Compras Governamentais com Incentivo à Indústria Local. Para isso, os processos licitatórios devem se destinar exclusivamente à compra de produtos fabricados por indústrias instaladas no estado do Acre. Seu objetivo é reduzir as desigualdades sociais e regionais e elevar a produtividade da indústria local. (ACRE, 2012). 
Além dos incentivos estaduais, o governo federal criou em 2015, através do Decreto $\mathrm{n}^{\mathrm{o}}$ 8.597, a Zona Franca Verde que foi regulamentada em 2016 pela SUFRAMA. A Zona Franca Verde representa uma espécie de Área de Livre Comércio (ALCs) que abrange os estados do Acre (Brasileia, Epitaciolândia e Cruzeiro do Sul), Amapá (Macapá e Santana), Amazonas (Tabatinga), Rondônia (Guajará-Mirim) e Roraima (Boa Vista e Bonfim).

É nesse contexto das políticas de ação do governo federal e estadual para alavancar o processo de industrialização em curso no estado do Acre que se inserem a Dom Porquito e a Acreaves.

A conclusão da pavimentação da rodovia BR-364, no ano de 1990, no trecho de Porto Velho-Rio Branco, foi outro fator que influenciou para consolidação da indústria, de maneira a facilitar o escoamento de seus produtos e o contato com outros mercados consumidores.

Além disto, conforme salienta Paula (2013), no ano de 1996, a população no Acre estava deixando de ser rural, ocorrendo a concentração de $65,3 \%$ da população no meio urbano. O que é de fundamental importância para a indústria, já que a mesma faz uso da aglomeração espacial para alavancar-se, ocorrendo a apropriação da mão -de -obra e uma melhor perspectiva para o consumo.

Desta forma, através das mudanças que foram ocorrendo no espaço, repercutiram para a consolidação da indústria, isto tudo devido ao objetivo de tornar o Acre um estado industrializado, "independente" e exportador, a partir do pressuposto de que, a matéria-prima e mão de obra disponíveis no estado seriam suficientes para manter a produção da indústria, de forma a expandir seu mercado consumidor para outros estados e países.

Entretanto, todas estas iniciativas e "sinais de industrialização" tornam-se contraditórias diante das estimativas atuais, pois através de estudos feitos pela Confederação Nacional da Indústria no ano de 2014, é notório que o Acre ainda não é um estado industrializado, tendo participação de apenas $0,1 \%$ no Produto Interno Bruto (PIB) de toda indústria nacional.

\section{O CASO DAS INDÚSTRIAS DOM PORQUITO E ACREAVES NO ESTADO DO ACRE}

\section{a. Dom Porquito}

O complexo agroindustrial da empresa Dom Porquito está localizado na cidade de Brasileia/AC e foi criado em 2013 durante o mandato do ex governador Tião Viana como uma iniciativa que ajudaria a consolidar o modelo econômico do estado baseado no Público-Privado- 
Comunitário (PPC). A empresa trabalha com a produção de suínos e visa a exportação de seus produtos para o Peru e a Bolívia através da rota do Pacífico.

Seu modelo de produção é caracterizado pelo sistema de Complexo Agroindustrial (CAI'S), pois esta indústria dispõe dos três setores fundamentais para o processo de produção do produto, sendo o setor de inseminação, o frigorífico e a fábrica de ração. Portanto, essa empresa apresenta características de um CAI, pois como já dito antes, se caracteriza pelo modelo de integração das técnicas entre os setores indústrias envolvendo desde a produção do insumo, a relação com o criador e a produção da mercadoria, embora não apresenta um nível de articulação e controle por grandes empresas e também não apresenta uma abrangência espacial global, somente em nível local e regional.

O setor de inseminação inicia com a coleta do material dos animais machos e a segunda fase é a inseminação do material recolhido na fêmea, destacando que os animais deste processo são selecionados criteriosamente pela indústria para garantir a qualidade do produto. Segundo a reportagem no site Notícias do Acre (2016), os animais desta fase foram adquiridos em Minas Gerais, na empresa Agroceres, que é parceira da Dom Porquito.

Depois da fase de gestação, que dura cerca de 115 dias, os animais são cadastrados normalmente entre cinco a sete dias, com vinte e um dias são desmamados é levado para outro galpão, onde são adaptados com uma alimentação balanceada e regrada de ração e uma papa que simula o sabor do leite materno. Finalizado este processo, os animais são direcionados aos produtores selecionados pela empresa, que ficam responsáveis pela engorda do animal, que quando atinge o tamanho de 110 quilos retornará para indústria.

Em meio ao processo de engorda destes animais, a empresa além de direcionar os animais aos produtores também fica responsável pela alimentação dos mesmos, disponibilizando os recursos necessários como a produção de ração destinada a alimentar estes animais. Esta ração é feita pela indústria com milho, soja e farinha de carne, recursos que são comprados em outros estados como Mato Grosso e Rondônia. Além da alimentação, a empresa oferece assistência técnica com veterinários e vacinas para os animais, sendo todos esses gastos descontados no valor da entrega do produto final.

Cabe aqui ressaltar um ponto importante desta empresa com relação a sua localização e o caso de se comprar recursos de outros estados. O interessante é que de acordo com Alder Cruz $^{3}$ (informação verbal), a empresa está localizada em Brasileia devido a Zona Franca

\footnotetext{
${ }^{3}$ Palestra com o diretor técnico da empresa Dom Porquito e Acreaves, Alder Cruz, realizada em setembro de 2018.
} 
Verde, como discutido anteriormente, localização que gera uma isenção fiscal nos produtos que a empresa compra como: PIS, IPI, ICMS e outros, o que leva a uma redução físcal de 15\%, fazendo com que não ocorra prejuízo devido a necessidade de comprar matéria prima de outros estados.

Ao retornar à Dom Porquito, os animais são direcionados para o abatimento, em seguida, encaminhados para o setor do frigorífico, onde será higienizado e cortados de acordo com as demandas do mercado consumidor. Além dos cortes inteiros e de partes do animal, tem também o preparo de linguiças, presunto, bacon etc. Finalizando esta etapa, o produto é embalado e destinado ao mercado consumidor, sendo mercados da região e também destinados aos mercados bolivianos.

Na empresa existem três tipos de marcas, a "Sabbor" responsável principalmente pelos produtos industrializados, como: linguiças, presunto e outros com um preço menor. A "Mister Pig" que incorpora os produtos com um valor mais elevado, sendo responsável também pelos cortes inteiros e embutidos dos suínos, e também a marca "Reffinatti".

A empresa conta com 116 produtores distribuídos nos municípios de Capixaba e Epitaciolândia. Com relação ao modo de remuneração destes produtores, Alder Cruz (informação verbal $)^{4}$, informou que a remuneração deste produtor parceiro se dá através da conversão de índices, levando em conta: a alimentação, quanto precisou de ração para produzir um quilo de carne; a taxa de mortalidade, quanto menor a taxa de mortalidade maior a conversão; o ganho de peso diário. Esses índices geram um percentual de produção do produtor, que será utilizado como base para sua remuneração, destacando que o preço do suíno pode variar entre 25 a 30 reais.

Para os aportes iniciais, o governo do estado do Acre ofereceu os recursos através de investimentos para a produção destes animais com linhas de créditos para a construção de galpões, oferecimento de capacitação destes agricultores realizado pela Seaprof para esse tipo de atividade industrial, pois é a agricultura familiar que está sendo trabalhado neste caso.

Nesse sentindo, cabe destacar que a indústria Dom Porquito é composta por capital privado e público, que segundo Alder Cruz ${ }^{5}$ (informação verbal) $25 \%$ das ações da indústria são do Governo através da ANAC (Agência de Negócio do Estado do Acre), 65\% de capital privado e $10 \%$ seria destinada para a cooperativa dos suinocultores, embora até o momento eles

\footnotetext{
${ }^{4}$ Palestra com o diretor técnico da empresa Dom Porquito e Acreaves, Alder Cruz, realizada em setembro de 2018.
} 
estejam apenas como vendedores de suínos (trabalhadores do sistema), ou seja, o modelo do PPC ainda não se efetivou com a Dom Porquito.

\section{b. Acreaves}

O complexo agroindustrial da Acreaves está localizado em Brasileia/AC, na região do Alto Acre, como um ponto estratégico devido à fronteira com a Bolívia e o Peru, o que permitiu sua criação com foco para a exportação.

O complexo pertence ao mesmo grupo das indústrias Dom Porquito, tendo como presidente Paulo Santoyo. O mesmo foi construído pelo governo do estado entre o período de 2005 a 2008, passando assim, por um regime de cessão durante 30 anos para a iniciativa privada.

Sua inauguração ocorreu em 2 de julho de 2008 e foi criada através do Pacto Agrário, ou seja, é um Programa de Apoio Científico e Tecnológico aos Projetos de Assentamento da Reforma Agrária, onde busca alternativas econômicas sustentáveis para evitar o êxodo rural, de forma que, agricultores e familiares adquiram conhecimentos sobre variadas temáticas, como por exemplo, as tecnologias.

O Pacto Agrário envolve parcerias com prefeituras, secretarias, universidades, etc. através de investimento por parte daqueles que desejam apropriar-se da terra, para que esta se torne mecanizada e para que exista uma mão de obra "capacitada" neste processo.

Os investimentos realizados na construção da empresa Acreaves ocorreram por meio de recursos do Banco Nacional de Desenvolvimento Econômico e Social (BNDES); do Ministério da Integração Nacional; do Tesouro Estadual e da Prefeitura de Brasiléia, totalizando um montante de 9,8 milhões.

A indústria Acreaves foi baseada no modelo Público Privado e Comunitário (PPC), sendo este um modelo bastante veiculado nas indústrias do estado do Acre. O modelo baseiase na cooperação entre o Estado, a iniciativa privada e o pequeno produtor, onde desta forma, o Estado participa do processo de regulamentação da indústria, assim como de seus investimentos; e o pequeno produtor será incluído como "sócio". Assim como expõe Schmidt (2015, p.338):

O público adentra no campo do privado (publicização do privado) e o privado adentra no público (privatização do público). As políticas públicas se realizam na presença de complexas redes de agentes comunitários, estatais e privados, entrelaçamento destacado [...]. 
Diante disto, a indústria Acreaves fora construída a partir de um projeto no qual objetivara ter como base a agricultura familiar, de forma que, o pequeno produtor passaria a ser sócio na empresa, o que ainda não se concretizou, sendo apenas produtores integrados à empresa e recebendo somente pelo produto vendido.

Para além disto, a Acreaves possui quatro etapas em seu conjunto produtivo: o frigorífico; a fábrica de ração; a fábrica de embutidos e a incubadora.

O frigorífico, situado na BR-317, é abastecido através dos frangos criados pelos pequenos produtores nos aviários, onde são transportados para o abate pela Acreaves. A capacidade que o frigorífico possui para o abate é de 40 mil aves por dia, entretanto, isto não ocorre, devido ao fato dos aviários existentes não possuírem capacidade de suprir esta demanda, ocorrendo então o abate de 25 mil frangos por dia (ACREAVES, 2019). Ainda com relação ao frigorífico, o mesmo produz cortes de frango, frango inteiro, miúdos de frango e carne mecanicamente separada (CMS). Totalizando o valor aproximado de 6,8 toneladas por ano, mesmo tendo ainda a capacidade de 9,8 toneladas ao ano.

A fábrica de ração é a mesma que atende a Dom Porquito. Ela possui capacidade de produzir 2 mil toneladas de ração por mês, porém a quantidade na qual a empresa está produzindo não atinge seu ápice. Os insumos utilizados para a sua produção são: milho, farinha de carne, fécula de mandioca, farelo de soja e óleo de gordura animal.

Dentre os insumos, $80 \%$ são adquiridos no estado do Acre, vindo de fora apenas o farelo de soja e o milho que são adquiridos dos estados de Mato Grosso e Rondônia. A perspectiva é de que a produção destes insumos venha a se expandir, para que futuramente todos eles estejam presentes no estado. Como exemplo disto, temos o consumo de milho, demandando 2.280 hectares de terra no estado, é um dos principais insumos na ração, fazendo-se, então, necessária a expansão de sua produção.

A fábrica de embutidos possui como nome patenteado a marca "Sabbor", tendo como produtos finais a mortadela, mortadela light, salsichão, apresuntado, linguiça entre outros.

Por fim, temos a incubadora, a mesma não fazia parte do complexo inicialmente, sendo desenvolvida posteriormente por meios de projetos da empresa. Diante disto, ela possui a capacidade mensal de comportar 640.000 mil ovos, onde são incubados 21 dias antes do nascimento. Atualmente, a incubadora gera 14 mil ovos por dia, onde o objetivo geral é o fornecimento destes ovos para os aviários, entretanto, supõe-se que diante da realidade dos aviários, os mesmos não sejam capazes de receber tamanha quantidade de ovos. 
Desta forma, através da entrevista realizada com o diretor industrial da empresa Alder Cruz $^{6}$ (informação verbal), é possível perceber que não ocorre exportação dos produtos produzidos pela Acreaves, pois os mesmos circulam apenas no estado do Acre, desmistificando a ideia de uma indústria exportadora privilegiada por sua localização. O entrevistado ainda relata que existem algumas dificuldades que dão ápice para o não crescimento da indústria, sendo estas as estradas mal pavimentadas, falta de formação de mão de obra, a centralização de recursos na capital do estado. Além disto, outro fator que comprova dificuldades com relação ao desenvolvimento da indústria, é o fato da empresa vender os frangos para outras empresas filiadas semanalmente, onde estas revendem o produto.

Com relação ao pequeno produtor filiado à Acreaves, o mesmo está incluso no processo de criação do frango. Para a ocorrência deste processo, é necessário que exista disposição de terras, onde nestas serão construídos os aviários para comportar o frango, e da capacitação desses produtores para a realização do projeto. Todos estes fatores necessários para a atuação do pequeno produtor são oferecidos pelo estado.

Atualmente, existem 60 produtores filiados à empresa, onde estes estão distribuídos no município de Brasileia e Epitaciolândia. A relação existente entre estes e a empresa é manifestada através de um contrato, onde é articulada a forma de atuação da empresa para com este produtor e vice versa. Neste, consta que a empresa tem como papel o fornecimento da ração necessária para a engorda do frango, sendo utilizadas seis rações diferentes ao longo do processo, também é fornecido através da empresa os pintinhos, medicamentos (caso necessário) e o transporte de todos estes, valores esses que serão descontados no momento da entrega dos frangos à Acreaves.

Nisto, o pequeno produtor passa a ser responsável pela engorda do frango, tendo a duração de aproximadamente 3 meses, onde ocorrerá a pesagem do animal ao fim do processo, o que determinará o valor do lucro deste produtor. Sendo assim, a empresa gratifica o pequeno produtor com determinado valor, transportando o frango de volta para o complexo agroindustrial, onde será abatido. Em casos de morte do frango, por motivos como a falta de energia, resultará na perda de aproximadamente $10 \%$ do valor que este produtor receberia.

\footnotetext{
${ }^{6}$ Palestra com o diretor técnico da empresa Dom Porquito e Acreaves, Alder Cruz, realizada em setembro de 2018.
} 


\section{CONSIDERAÇÕES FINAIS}

Ao compreender a organização, investimento e logística atual destas indústrias acreanas podemos entender brevemente sobre a realidade industrial, seus percalços e suas expectativas futuras para o estado do Acre.

É fato que ambas as indústrias foram construídas com o objetivo de torná-las independentes e exportadoras, isto é notório diante da capacidade de produção em que os complexos apresentam, mas o que na realidade não ocorre, ocasionando uma baixa produção relacionada à sua capacidade.

Nesse sentido, tem-se um processo industrial assentado, prioritariamente, em produtos de base extrativista e agroindustrial, envolvidos em um setor produtivo com baixo nível tecnológico e baixa oferta de matéria prima para a produção, o que permite que as indústrias tenham uma baixa produtividade e somente um alcance comercial regional, o que se evidencia na ínfima participação do Acre no PIB nacional com relação aos produtos industrializados.

Outro destaque é que o modelo do PPC adotado pelo estado não se consolidou, pois referente a participação do camponês ainda existem muitas lacunas a serem solucionadas para que estes possam de fato serem efetivados no modelo com uma participação ativa, e não somente como um trabalhador.

Logo, é perceptível que o estado do Acre ainda não é um estado industrializado, mesmo diante de várias iniciativas que o estado gerenciou, estas não foram suficientes para salientar as necessidades de produção da indústria, tais como a matéria prima, nível tecnológico e o mercado consumidor.

\section{REFERÊNCIAS}

ACRE. DECRETO $\mathbf{N}^{\mathbf{0}}$ 4.196, de $\mathbf{1}^{\circ}$ de outubro de 2001 (a). Programa de Incentivo Tributário para Empresas, Cooperativas e Associações de Produtores dos Setores Industrial, AgroIndustrial, Florestal, Extrativo-Vegetal e Industrial Turística do Estado do Acre. Disponível em: www.sefaz.gov.br. Acesso em: julho de 2018.

ACRE. DECRETO $\mathbf{N}^{0} 4.198$ DE $1^{\circ}$ de outubro de 2001 (b). Política de Incentivos às Atividades Industriais no Estado do Acre. Disponível em: www.sefaz.gov.br. Acesso em: julho de 2018.

ACRE. LEI No 2.548 de 17 de fevereiro de 2012. Programa de Compras Governamentais com Incentivo à Indústria Local. Disponível em: www.sefaz.gov.br. Acesso em: julho de 2018. 
CADEIA DE PRODUÇÃO DO FRANGO SE CONSOLIDA NO ALTO ACRE. Acre: ORB.net, 2014. Disponível em: http://www.oriobranco.net/noticia/acre/cadeia-de-producaodo-frango-se-consolida-no-alto-acre . Acesso em: 15. jan. 2019.

CARLOS, Ana Fani A. Espaço e indústria. São Paulo: Contexto/EDUSP, 1988.

MENDONÇA, S. R. A industrialização brasileira. 2. ed. São Paulo: Moderna, 2004.

MOREIRA, Ruy. A Geografia do Espaço Mundo. Conflitos e superações no espaço do capital. Rio de Janeiro: Consequências, 2016.

MOURA, J. L. P. Tropos: Comunicação, Sociedade e Cultura. Os Mitos do Desenvolvimento no Acre da "Frente Popular". Rio Branco, v. 5, n. 2, p. 1-16, dez. 2016.

NOTÍCIAS DO ACRE. Dom Porquito transforma vida de produtores rurais no Alto Acre. Disponível em: http://www.agencia.ac.gov.br/dom-porquito-investindo-naproducao-desuinos-para-exportar-do-acre-pelo-pacifico. Acesso em: 22 de jan. 2019.

PAULA, E. A. (Des) Envolvimento insustentável na Amazônia Ocidental: dos missionários do progresso aos mercadores da natureza. Rio Branco: Edufac, 2013.

PONTE, K. F. da. O Desenvolvimento Sustentável e o Controle Social da Natureza e do Trabalho: Um estudo sobre a Fábrica de Preservativos Masculinos de Xapuri (AC). 360p. Tese (Doutorado em Geografia). Universidade Estadual Paulista, 2014.

SCHMID, J. P. PÚBLICO, COMUNITÁRIO E PRIVADO: Direitos e Bem-estar na Perspectiva do Paradigma Comunista. Unoesc, Joaçaba, v. 16, n. 2, p. 333-360, jul./dez. 2015. DOI: https://doi.org/10.18593/ejjl.v16i2.4586 